\title{
English as a Second Language
}

\author{
Dr. Disha Sharma
}

\author{
Asst. Prof. English, Govt. PG College Karnprayag, Chamoli, Uttarakhand, India \\ Email-disha.8126@gmail.com
}

\begin{abstract}
English is spoken as a second language by many countries such as India, Pakistan, Bangladesh, Shri Lanka, Nigeria and Tanzania. In these countries English is spoken as a non-native or second language, and used for various purposes official, educational, social and interpersonal. In the countries such as Russia, Japan, Germany, France and Italy, English is used as a foreign language. A second language is one which is used for various purposes within the country while a foreign language is used. In learning a second language we will find that vocabulary is comparatively easy. However, in some countries like the United Kingdom, the United States of America, Canada and Australia, English is native or first language. As we listen to a person speaking our native language we hear not only what is said but also certain things about the speaker. English is first, second or foreign language. Children learn native language from a very early age to respond to sounds and tunes which their elders habitually use in talking to them. Second language is generally learnt later in life. The second language is learnt after the child has mastered the first language, his/her learning of the second language is influenced by the first language.
\end{abstract}

Keywords- English, Second, Language, Spoken, Country.

The three major components of language, as far as language lies within the scope of linguistics, are the structure of expression, the structure of content, and vocabulary. The latter comprises all the specific relations between expression and content - in the familiar terminology, words and their meanings.

Vocabulary comes and goes; it is the least stable and even the least characteristic of the three components of language. That portion of the Vocabulary which changes most freely is sometimes referred to as "Slang". But even staid and dignified words and constantly being created and continually passing out of active use, to be preserved only in the literature which is dated by their very presence. Certain types of words are more transient then others, none are absolutely immortal. Even the most familiar and commonly used word, which might be expected to be most stable, have a mortality rate of about twenty percent in a thousand years.

In learning a second language, $\mathrm{u}$ will find that vocabulary is comparatively easy, in spite of the fact that it is vocabulary that students fear most. The harder part is mastering new structures in both content and expression. A person's voice serves at least two functions in communication. One is linguistic, in that it serves as the vehicle of the expression system $f$ language. The other is non - linguistic, it carries information of a quite different kind about the speaker.

We may defined a phoneme as a feature of the expression of a spoken language by which one thing that may be said is distinguish from any other thing which might have been said. There are two things about phonemes that must be explicitly pointed out in anticipation of any such presentation. Phonemes are part of the system of one specific language. The phonemes of different language are different, frequently in commensurably. It is for this reason that a foreigner hears only jumble which he cannot repeat. The sound of the unfamiliar language does not fit into his phoneme system, and so he can comprehend no order in a simple utterance. Linguistics must start with through investigation spoken language before it proceeds to study written language. This is true of language with long histories of written literature such as English, no less than those as isolated tribes which have never known of the possibility of writing.

Grammar forms one part of the science of language, this science is itself a part of the natural history of human being. Its method is in substance that of natural history of human beings. Its method is in substance that of natural science generally; it consists in accurate investigation of our object and in conclusions founded upon that investigation ..... by grammar be mean the scientific comprehension and explanation of the sounds, the forms, the function of words and their parts and the construction of sentences. Language is to be treated clinically in line with procedures that had been developed by natural sciences.

English as a second language ESL programs are also organised for the students whose first language is other than English or is a variety of English significantly different from that used for Ontario schools. Students in these programs have had educational opportunities to develop appropriate first language literacy skills.

Some students have attended schools, while others may never have attended. Students have a range of oral English proficiency. Some familiarities may have experienced great difficulties, and may still carry the 
burden of separation and loss. International organizations report that numbers of refugees come from situations involving conflict and trauma. As well, issues such as unresolved asylum claims, financial hardships, limited facility with English, outstanding health issues, and the is olation and the newness of their lives in present daily challenges. They require many supports to rebuild their lives. At the same time, they are survivors. They often display adaptability.

ELLS with limited prior schooling lack academic experiences, but not life experiences. Their need for intensive literacy and language support programs is balanced by the cultural and linguistic capital that they bring with them. They are likely to bring curiosity about their new country and very little experience with school routines and expectations. Students may have had little formal schooling; they have required other knowledge and learning. Educators who value and build on that prior knowledge and experience help these students succeed in school.

English is an international language, and varieties of English sometimes referred to as dialects are spoken around the world. Standard English is the variety of English that is used as the language of education, law, and government in English- speaking countries. Some varieties of English are very different not only in pronunciation or accent but also in vocabulary and sentence structure from the English required for success. Some varieties are so different from Standard English that may linguists consider them to be languages in their own right.

Some immigrant families chose to leave their country of birth and come to Canada and some have been forced to leave by circumstance beyond their control including war, violence, famine, poverty, natural disasters, or political instability. Some English language learners with limited prior schooling have experienced significant emotional trauma which may affect their ability to learn and to adjust to their new country. Being immigrants is not their total experience but rather their most recent past.

In some places some females may have had fewer opportunities to attend school than their male siblings. A student from rural setting may experience more anxiety adjusting to an urban environment then a student who has experience city life. Teacher can provide a consistent safe place in which to learn, with clear parameters, where value of equity and inclusion are evident and demonstrated and sure that learning environments reflect the diversity of learners, so that all students can see themselves represented in their classrooms recognised that the learners needs go beyond academic needs. Learn about geographical, linguistic, and cultural backgrounds of students through reading, settlement resources, and positive, informal interaction with students.
Students names and greet the students by name when they arrive in class. For these students, learning the new rules and understanding the expectations schools have for all students in both exciting and frightening. This is an opportune time to teach students about the school's expectations of and for them. Students whose language and culture are valued gain confidence in their abilities to succeed in learning. They need consistent and appropriate support at school.

The students in India can be categorized into two; the one is having the regional language as medium of study from the primary level and the other is having English as the medium of the study. Hence, the problem of teaching English as a second language, to the Indian students starts from the pre- schooling. Environment and family background play vital role in success of learning process. For example, countries like India, where majority of the people are farmers, have the poor background in the education. Moreover, the income of majority of the families is not adequate. That is why the parents are not interested in giving good education background to their children. In contrast, they are willing to engage the children in some jobs to earn money. The first category of the students care almost compelled to attend their classes under the trees. Majority of the students are coming from village and also their parents are farmers and uneducated. If the nature fails, the survival of the farmers will be questionable. Hence, the students are mentally discouraged due to family conditions. In the second category, the students are having enough background in basic education since their parents are educated and they do not depend on the nature much. Many of the students from second category are joining in English medium school and hence, they do no find much difficulty in pursuing their higher education.

More over majority of the families of second categories are dwelling in towns and cities and hence, they have easy access of quality education. But the first category of students is scoring good marks the examination conducted. It proves that they are having good writing skill in English. They have to be given training in oral English communication.

When we learn our first language, our brain, mind 'tunes into' the way of particular works, and we learn to pay attention to particular cues to meaning that are most helpful. When we meet a new language, are brain and mind automatically tries to apply the first language experience by looking for familiar cues. Part of learning a foreign language is developing new understanding about the particular cues to meaning that the new language of offers and that differ from those of our first language.

A teacher's primary role is not only to enable the students to understand what he is intending to say or teach. It is also the duty of the teacher to understand what the student 
wants and says. In teaching learning process, two things play the vital roles; one is the delivering capacity of the teacher and the other one is receiving capacity of the students. Without the two aspects, the teaching-learning process will not be a successful one. Teaching- learning process is just like making sound by clapping. Without two hands we cannot clap. Like that without a right teacher and the students, the teaching learning process is meaningless. Teaching should be a worthy of learning a concept deeply and broadly. Teaching should facilitated the students to face the world which full of political, social, international as well as personal controversies, without fear. It should give self- confidence to the students. By the effective teaching, the students should be enabled to go for right choices, judgements and also decisions individually. In the process to teachinglearning, the teacher should try to understand the students first.

Success of a teacher in his/her attempt in enabling the students to understand what is the concept taught by the teacher depends on the methods he/she applies. The teacher may be a good, but the students' physical problems may lead him to ignore the teaching. Sometimes, the background of family of the students may drive him to be dull. Hence, the teacher should take into account everything. At the school level the teachinglearning process is checked up the teacher by repeated class tests and examinations. At the college level also the same traditional method of examination is used. The only difference is the volume of syllabus prescribed for the college's students will be more than that of the school level.

\section{REFERENCES}

[1] M (Laughlin, B. 1987). Reading in a Second Language: Studies with adult and Child Learners. In S.R. Goldman \& H. T. Trueba (Eds.), Becoming Literature in English as a Second Language. Norwood, N. J: Ablex Publishing.

[2] Chaudhary Sanjay. English as a Second Language. New Delhi: DPS Publishing House, 2011, pp. 70-77.

[3] Priya Hosali; S.V. Parashar. Phonetics and Spoken English. Hyderabad: English and Foreign Language University, 2012, p.2 